\title{
Recovering from Libet's Left Turn into Veto-as-Volition: A Proposal for Dealing Honestly with the Central Mystery of Libet (1983)
}

\author{
Conal Boyce \\ Century College, St. Paul, USA \\ Email: conalboyce@gmail.com \\ Received November $3^{\text {rd }}, 2011$; revised December $10^{\text {th }}, 2011$; accepted December $18^{\text {th }}, 2011$
}

\begin{abstract}
With certain topics the general reader experiences a double-whammy wherein one must peer through a curtain of needlessly obscure jargon to try glimpsing something that is inherently weird in nature. Bell's nonlocality was once such a topic, but authors have had considerable success over the years in showing where the line is between the enigma itself (in nature) and the human-made oddities surrounding it (in physics). Libet-ology has yet to undergo that de-mystifying process. Accordingly, our first order of business here is to restate its basic tenets in plain English so that only nature's inherent puzzle is left on the table, free of certain peculiarities of the existing technical literature. We also address the question of the central topic versus its byways, as alluded to by 'left turn into veto-as-volition' in our title (On the final page of Libet's landmark paper, there is an effort to resurrect free will in the same breath that implicitly just killed it. In this way, the founder of the field placed it into perennial disarray and left its true message in obscurity for decades). In the ensuing parts of the paper, we look outside the field to see how hypnotherapy and Hinduism might shed light on it.
\end{abstract}

Keywords: LIBET; Volition; Free Will; Free Won’t; Mental Timing; Ethics; Hypnotherapy; Rossi \& Cheek; Hinduism; Neurophysiology; Readiness Potential; Bereitschaftspotential; EMG Onset; Downward Causation; Unconscious Processes

\section{Introduction}

Definition of terms and scope: In the text I will make frequent use of the term "Libetology" - an admittedly graceless but necessary shorthand device to avoid reiterations of the following string of references: Libet et al. (1979, 1983), Libet (1985, 1999, 2006), Penrose (1989), Klein (2002a), Obhi \& Haggard (2004), Hallett (2007), Matsuhashi \& Hallett (2008), Kühn \& Brass (2009), and Schooler (2010). i.e., these twelve will comprise my primary frame of reference; thus, an ad hoc paring down of the field to a size that I, as an outsider, find manageable. Also, in connection with Figure 1, there will be a "programming" thread, supported by references to Klein (2002b), Obhi \& Haggard (2004), Murphy et al. (2009), and Vohs (2010).

Following natural contours of the field itself, one becomes aware of four primary topics in Libetology.

\section{The Central Mystery (A)}

Libet (1983) leads to a genuine puzzle regarding self and volition. As an individual, I "know" I have free will and I accept responsibility for my actions; at the same time, the science says volition (as we regular folk think we understand it) is only a time-lagged illusion, suggesting a planet populated by automatons. How can these be reconciled? Not easily!

\section{Veto-as-Volition (B)}

Closely bound to the central mystery but casting a decadeslong shadow over it is veto-as-volition (later canonized as free won't), which appears immediately as a non sequitur in Libet et al. 1983: p. 641. In retrospect, we see that page 641 was only the tip of an iceberg comprised of Libet's implicit theology founded upon a special brand of stealth-dualism; this is described in Klein (2002b): pp. 329-330 (but note also the apology/rationale for Libet on pp. 331-332). These matters create a significant drag on the whole field. They are addressed below in the section called Doublethink.

\section{Ascribed-Time-of-Perception under the Microscope (C)}

This topic holds a degree of intrinsic interest, yes, but in relation to (A) above it strikes me as hair-splitting. I can't help wondering if some who dwell upon this line of investigation are not attracted to it as a form of denial or avoidance of the central mystery. \$2.1.1 in Hallett (2007) is devoted to this cottage industry. Given Matsuhashi \& Hallett (2006), one might expect the topic had been laid to rest. Not so. A "lively literature" on this topic is still alluded to in Baumeister et al. (2010): p. 49, for instance.

\section{More Felons at Large, More Liars at Home (D)}

Those who gravitate to this topic hold roughly the opposite view from those who dwell upon topic $\mathrm{C}$. Far from denying the implications of Libet, these individuals seem impressed by the preponderance of evidence that free will is dead and wish to strategize now about the ethical fallout that might occur once the news gets out. In the extreme case, the prison gates would 


\section{BOYCE}

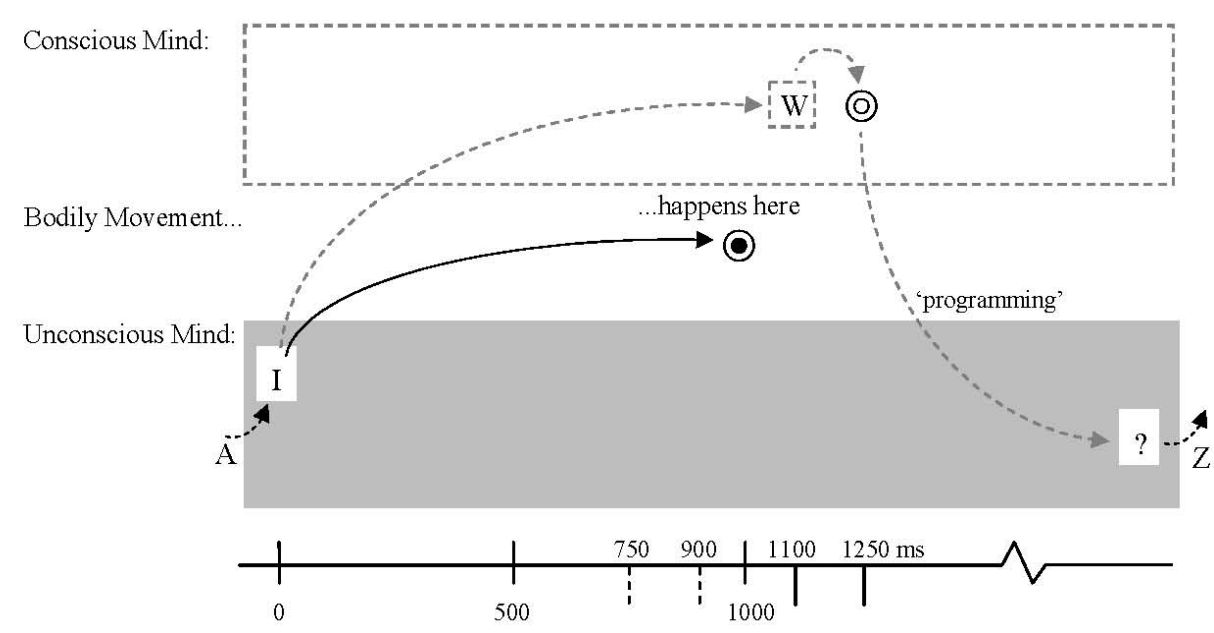

Sources: please refer to Appendix A

Legend

$\mathrm{I}=$ Inception of an event in the unconscious. (In the literature, this is 'RP' or 'BP'; see def. in text.)

$\bigcirc=$ the event itself, e.g., a finger is lifted. (In the literature, this instant is called 'onset' or 'EMG onset'.)

$\mathrm{W}=$ subjective time of Willing the event (or Wanting it; see trivia note below).

() = subject's false notion of when Movement occurred. (In the literature, this is the label ' $M$ '.)

Labels 'A' and ' $Z$ ' pertain mainly to section 3 of this paper, where the labels 'Conscious Mind'

and 'Unconscious Mind' will also be revisited (and replaced).

Where to draw the notional lines for solid fact, fuzzy fact and conjecture:

The solid arrow from 0 to $1000 \mathrm{~ms}$ joins the two objective data points (facts) that anchor us.

The dashed arrow running from ' $I$ ' at 0 to ' $W$ ' at $1100 \mathrm{~ms}$ is open to some (limited) discussion:

As drawn, it represents Hallett's (approximation of) Actual Time of Perception of W. If opting to show his

Ascribed Time of Perception, we would place W and $\odot$ at the dashed-line positions, 750 and 900 , in lieu of

1100 and $1250 \mathrm{~ms}$. So, let's call this the region of 'fuzzy fact' (from 750 to $1250 \mathrm{~ms}$ ). Note however that any

way we slice it, this region marks the death of free will. (This is why topic $\mathrm{C}$ in the Introduction is a

pseudo-issue, off the table.) All that remains is a (doubly false!) illusion of free will, where the short arrow joins $W$ to $@$.

The arrow starting at $1250 \mathrm{~ms}$ and ending at some arbitrary point ('?') to the far right is a conjectured link from the conscious mind down to the unconscious. More specifically, this arrow represents a supposition of programming the unconscious as discussed in Obhi \& Haggard 2004 ("ongoing computations related to a forward model', p. 365) and in Murphy et al. 2009 ('A key tool in understanding how free will may arise [in a complex, post-Libet framework] is downward causation..Top-down causation is usually neglected, and is therefore emphasized [in the book's title]'). See also Vohs, p. 66, on 'Conceptualizing the planning of actions', also Gibbs on '...programming our unconscious mind' under Wegner (2002) in the Annotated Bibliography below.

Trivia: In Libet (1983) p. 623, etc., W = 'wanting', but later authors routinely mistakenly assume that Libet's $\mathrm{W}=$ 'will'; e.g., see Hallett, p. 2.

Figure 1.

Summary of various Libet-related experiments (plus a "programming" conjecture).

be thrown open since blame could no longer be attributed. Note the double whammy: Not only would the tectonic shift in attitude cause a release of felons into the general population, but it would likely induce higher rates of lying [and criminality] among us all. The latter scenario has already been demonstrated by Vohs and Schooler, as referenced in Schooler, 2010: pp. 194-195. Note however that their lying-rate studies involve college-level subjects who are asked to read from Francis Crick's The Astonishing Hypothesis. Meanwhile, Smilansky has remarked that, "Humanity is fortunately deceived on the free will issue" (quoted in Schooler, 2010: p. 192). Whereupon one has to wonder: Will the public ever be in a position to compre- hend/believe in Libetology? Given the intrinsic weirdness of the field, the answer might be no, in which case one's concern about the prison gates opening might be allayed, or at least deferred for some decades.
In Libetology, we explore topics A and B above (and have little more to say about topics C and D outside of this introduction). In New Context(s), we try picking up the lost thread from 1983 in a slightly off-beat framework: the "mind-brain/brainbody" model of hypnotherapists Rossi and Cheek (I find their model compelling but I prefer to use the nomenclature "headbrain/body-brain" for reasons explained below). Also, since Hinduism is the oldest and best authority on introspection, one wishes to see how/if all this might be re-synthesized in that broader context (Quite well, as it happens, as indicated in Triptych and Concluding Remarks.).

Exoticism? Perhaps my forays into hypnotherapy and Hinduism look recherché at first glance. But don't forget topic D above. I may have couched it in semi-facetious terms (felons running amok), but unlike topics $\mathrm{B}$ and $\mathrm{C}$, topic $\mathrm{D}$ is a serious one. It tells us to wake up and try to honestly finish what Libet 
started before it is too late. And for that task, we need "all the help we can get" from whatever far-flung quarter.

\section{Libetology}

\section{The Central Mystery}

Please refer to Figure 1 where I give my synopsis of Libetology, based on sources as early as 1983 and as late as 2010, as detailed in the Legend and in Appendix A.

Admittedly, the story told by Figure $\mathbf{1}$ is very strange, so it bears repeating in a slightly different form before we proceed:

At the outset, to provide some minimal context I say, "She [the subject] decides to lift a finger". But already, with that bland-seeming statement, I'm in trouble. How so? Because any conventional definition of "she" or "the subject" will be at odds with the ego-less zone depicted at the lower-left, where we need to start the narrative. The solution to this dilemma: On faith, you must promise to set the puzzle aside for now and read on.

The finger-lift that "she" has somehow "decided upon" has its Inception (I) at the time labeled zero. In the literature, this is the moment of the readiness potential (RP) alias Bereitschaftspotential (BP) of Kornhuber \& Deecke (1965). This is where her body starts its journey toward being physically able to perform such a movement. Since the RP correlates with nothing in her conscious awareness, we must assign it by default to some kind of "unconscious awareness" (For now, please pardon the oxymoron. After we've introduced Rossi \& Cheek, 1994, we will find a substitute for the term "unconscious", which lingers in the literature from the time of Freud, and short-circuits understanding). The event itself occurs at the $1000 \mathrm{~ms}$ mark (arbitrary icon with solid center). Still later, at $1100 \mathrm{~ms}$ or "W", she feels that she is just now willing the event. Finally, she imagines that her (supposedly) willed event happens at $1250 \mathrm{~ms}$ (icon with hollow center), now a full $5 / 4$ seconds beyond inception and a quarter-second after the event. Is she not one of the strangest creatures in the cosmos?

Although the literature includes variations on the theme, the concomitant nuances do not change by one iota the basic weirdness of the model just presented. In short, "she" is anyone and everyone who ever lived (It gets worse. "Nowhere in any formulation of physics that we know of does the issue of a special point in time called 'now' ever occur"; Lederman \& Hill, 2008: pp. 341-344. Adding insult to injury, physics thus reminds us that the slippery "now" we've been chasing probably isn't real anyway!).

So much for defining the central mystery, as I call it. The following advice from Sir Arthur Conan Doyle seems tailor-made to the circumstance: "Once you eliminate the impossible, whatever remains, no matter how improbable, must be the truth". In other words, rather than flee Figure 1 in dismay, let's be adults and squarely face "whatever remains", namely that free will operates somehow in the realm of the so-called unconscious. Specifically, let's try a two-pronged attack, divided along the lines of long-term/short-term mental processes.

It is actually not so difficult to imagine the conscious mind instructing or "programming" the unconscious with reference to events in the mid-term or long-term future, e.g., for "impression management" to borrow a term from Vohs (2010). Already this recaptures one aspect of the free will "Paradise" that we feared was "Lost", and it reinstates in large measure Individual Responsibility. Relative to Libet (1983), this is something extra, represented by the large downward swooping arrow in Figure 1. Now we return to Libetology proper:

Meanwhile, on the left side of the figure, time is measured not in hours or months but in fractions of a second. At first blush, shouldn't it be just as easy to imagine the unconscious mind generating the events in this region? After all, the vernacular has a ready-made phrase for this: "doing things on autopilot" (e.g., the subroutine we call upon for steering a car while speaking to a passenger). However, to encompass all that is symbolized by the solid arrow on the left side of Figure 1 we would need to greatly extend this autopilot notion to encompass everything we do (e.g., speaking to the passenger) - and that in turn would evoke a picture that is highly repugnant: earth inhabited by a species of zombies or automatons who steer cars and talk "mindlessly". For now let's say we've reached an impasse, and revisit that piece of the puzzle in New Context(s) for Libetology.

\section{Doublethink}

Considering the profound implications of his 1983 paper, it seems odd to me that Libet has so little name recognition outside the immediate field; or, more to the point, that the findings of 1983 are not known to the public (cf. Smilansky's words above). Here is a related thought, from Klein (2002b): “...why has there been continuing controversy over the past 20 years regarding Libet's volition experiments...when there is so much agreement on the basic facts?" Klein then introduces the term "chronotheology" (from Bolbecker et al.) and goes on to separate Libet's science from Libet's theology, finally invoking quantum mechanics to try rationalizing Libet's stance (Klein, 2002b: pp. 329-332). My own critique of Libet will be less sympathetic: In the final few sentences of his 1983 paper, Libet jerks our attention away from the astonishing findings on $\mathrm{pp}$. 623-640 into ruminations on veto-as-volition: "There could be a conscious "veto" that aborts the performance even of the type of "spontaneous" self-initiated act under study here. This remains possible because [W appears a substantial time before EMG]"; p. 641, my italics. (Possible but improbable. Try telling the parent who just locked Baby and keys into the $90^{\circ} \mathrm{F}$ car that "you should have been quicker and exercised your veto power"; compare Penrose, p. 443.) Instead of dealing honestly with the death of free will (as classically understood), Libet has taken a left turn into the area that will eventually be canonized as free won't (in Obhi \& Haggard, 2004: p. 360). Implicitly, Libet has forsaken his own best idea. This partially explains his lack of name recognition, even after decades.

Evidence of the lingering problem is conspicuous in Hallett (2007). As implied elsewhere in this paper, I regard Hallett's work as first class, but his use of language threatens to obscure his results. For example, his title indicates that the topic will be "Volitional Control" and "Free Will", but the ensuing text shows in excruciating detail that there is no such thing as volitional control and no such thing as free will. When Hallett writes of the "voluntariness of a voluntary movement" in $\S 1.0$, a reasonable person assumes that the upcoming topic must be voluntary movement. Wrong. From context, one begins to realize, circa $\S 2.3$, that Hallett is using the term to denote a subject's illusion of voluntary movement. Apparently he views "voluntary movement" not as a meaningful English term, rather as an arbitrary technical tag. We expect engineers to (ab)use language in that passive-aggressive manner when compelled to 
write their much-despised "documentation", but we are taken aback to see it in a scholarly context. In Endnote 10.1 Hallett writes: "Free will exists, but it is a perception and not a force driving movement." Since the sentence itself is nonsense, one might speculate that its author is treating "free will" as another arbitrary engineering-style tag. Or, could these linguistic peculiarities signal a thread of doublethink in Libetology?

The term "doublethink" made its debut in 1948 in Orwell's novel, 1984. Since then, generations of students have dutifully told their English teachers how aghast they are at the idea of slate-eyed bureaucrats promoting doublethink from windowless towers of the future. But the practice of doublethink goes back to the mists of prehistory, and it pops up around us all the time in areas that have nothing to do with Orwellian politics. For example, every child growing up in the West will likely experience a period of doublethink lasting a week, a month, or perhaps even a year or two during which the Santa Claus belief is recanted in one part of the mind, yet protected in another part of the mind, for old time's sake. For half a century, the particle physicist has held his mind in just such a state of doublethink-suspension, knowing about the triple blow to parity in 1957 (separately for beta-, muon- and lamba-decay) yet laboring ever after with quasi-religious fervor to find creative accounting tricks that will "prove" the cosmos cares about symmetry just as much as he does, in allegiance to Noether's theorem. Thus the bizarre language of particle physics, where one must avoid any hint of cosmic indifference to symmetry, and speak rather of "failure of conservation of symmetry" or "evidence of parity nonconservation". Partly this is the fault of the English language: the word "symmetry" may be conveniently negated by prefixing " $a$-" but to negate "parity" one would have to coin an ungainly new term. But this shortcoming of language suits the psychology of the physicist just fine, for he wishes fervently to hang on to symmetry forever (see Lederman and Hill, 2008: pp. 20-25 and 176-181). If a child at age eleven filled his journal with "observations of nonconservation of Existence-of-SantaClaus" his parents might call in a psychiatrist; and yet, in physics such thinking is routine.

Clearly, then, Libetology is not alone in the world, in suffering bouts of doublethink rooted in ambivalent feelings about experimental facts that threaten to overturn cherished beliefs. But what to do? If one wished to see Libet's name elevated to its rightful place, in lieu of Klein's approach alluded to earlier, I would simply draw the line between decades of "volition" fantasy and the reality of free will's demise (analogous to the Downfall of Parity). With Libet's name thus "cleared", one would feel free to change the focus to something more promising such as "programming", as introduced in connection with Figure 1, and revisited below.

\section{New Context(s) for Libetology}

\section{The Head-Brain/Body-Brain Model}

Paraphrasing from Rossi \& Cheek (1994: pp. 61, 160, 165, 275, 345, and passim): Each of us possesses a head-brain AND a body-brain. (Nomenclature: Where I speak of the head-brain and body-brain, they use the rather confusing terms "mindbrain" and "brain-body".) Specifically, the distinction they draw is between 1) the classical neural transmission of information, rapidly through the nerves only, and 2) the "information substance receptor system [operating slowly through] the blood, cerebro-spinal fluid, lymph, intercellular spaces of [the] brain, etc." (p. 52). They speak also of a contrast between "fast anatomical information addressing of the nervous system and the slower parasynaptic chemical addressing system".

To those familiar with Biblical Greek or Classical Chinese or Indo-Tibetan religion, this notion of brain-stuff residing elsewhere than in the cranium should not seem strange. Even in modern Chinese, for that matter, the word for "heart" still serves double duty as the word for "mind". (See also Dorje, pp. 21 and 405 re the correspondence of the Indo-Tibetan syllable Hüm with the concept of heart/mind). Caveat: In Rossi \& Cheek, many organs are mentioned-among them the thyroid, spleen, kidney, and ovaries; also cells in a generic sense-but never the heart specifically; so it must also be noted that the oriental heart-as-mind concept is suggestive only in a general way of their detailed western model.

Even though Rossi \& Cheek's long-ago (1994) publication is of narrow provenance (hypnotherapy), it represents an important advance in our general understanding of the mind, I think. Moving now into my own characterizations (which may sometimes go in a slightly different direction than Rossi \& Cheek intended), I would say the head-brain is fast and modern, though often rather obtuse relative to the body-brain, which is slow and ancient but (ironically) better "informed" about events as they transpire. Also, it is noteworthy that the head-brain can be turned off, in its little nightly death called "falling to sleep". By contrast, the body-brain never sleeps-hence its potential for greater intelligence and deeper knowledge.

Note how remarkably compatible Rossi \& Cheek's model is with Figure 1 above, even though the latter comes at the problem from such a different direction. In Figure 1, suppose we replace the lingering Freudian labels "conscious" and "unconscious" by "head-brain" and "body-brain". We can now resume our discussion of "programming", by bringing into the picture the small arrows labeled $A$ and $Z$ in Figure 1. My intention is that these two be read as "the same arrow" so that the diagram depicts a full cycle involving both short-term programmed events on the left and long-term programming activity on the right. (This is highly schematic. In a more realistic model we would show other kinds of input in the vicinity of A, such as visual data from the environment, and so on.) Any time we engage in the kind of self-programming called "impression management" (alluded to earlier), we are already implicitly acknowledging that the body-brain possesses a respectable, full-functioning mind. This is in sharp contrast to the cesspool evoked by Freud, or the primeval "bug"-ridden mess proposed by Buonomano (2011). Of course there are some "bugs", if you like, that can benefit from course-correction by the head-brain, but the far larger challenge is learning how to "talk to" the body-brain about its execution of the medium-term and short-term actions that comprise one's life! The A-Z loop is there. Our job, if we wish to stop being a planet of zombies who operate on a half-second delay, is to figure out how to exploit the loop - in the direction of more ethical behavior if one is a regular citizen, or in the direction of introspection if one has mystic aspirations.

In the meantime, we should not be too surprised when our public figures commit acts of pure folly (Weiner's tweeted wiener), or when a sociopath of phantasmagoric dimensions blossoms on the scene (Florida v. Anthony). To explain such cases one could postulate that all "programming" has simply broken down. Or, in still other circumstances, it may happen 
that the body-brain issues a unilateral communiqué, deliberately going rogue against the programming cycle. This idea will be explored in the next section.

\section{An Alarm Clock "Dream" or the Body-Brain Delivering a Communiqué?}

To balance my heavy reliance on metaphor and abstraction elsewhere, this will be an interlude about some phenomena that are specific, albeit purely anecdotal and subjective. For years, I believe my "body-brain" has tried to announce its presence to my "head-brain", but the message was garbled until I became familiar (only recently) with Rossi \& Cheek. Most days of the year, my alarm goes off and I simply get up, like everyone else. However, on three or four random days of the year I experience something like this instead:

A: At 7:00:00 a.m., my body-brain (the one that never sleeps) hears the alarm in real time.

B: At 7:00:03, my head-brain, still half asleep, takes note of event "A" and hazily classifies it as "a dream but not really a dream" (This layer seems to jibe with Freud's proposed "preconscious" level).

C: At 7:00:06, my head-brain wakes up fully. At this moment, the alarm seems louder, and qualitatively "real". My head-brain briefly puzzles over "B" - that moment of having glimpsed "A" (Comment on the pseudo-times indicating three seconds and six seconds past the hour for B and C. I would characterize those numbers as "twice removed from reality": First, they are only impressionistic; secondly, they are impressions of subjective time. Meanwhile, the objective times for B and $\mathrm{C}$ might be at a half-second and one second past the hour, i.e., of a time granularity compatible with Figure 1. A certain Chinese story comes to mind here: a man puts a pot of rice on the fire, takes a nap, dreams an entire lifetime in the time it takes the rice to finish cooking).

This $\mathrm{ABC}$ sequence is blessedly simple compared to the scenarios I concocted pre-Rossi \& Cheek to try explaining these "alarm clock dreams", armed only with a smattering of Libet (1979) via Penrose (e.g., perhaps all existence is a sham, only the playback of 4D movie, in which case time-lags would be a non-issue; or, perhaps my unconscious mind contains its own precise clock and mischievously tosses out a preview of the alarm moments before the physical alarm sometimes, just to spook me; etc.). Simple or not, the new vision is not immediately welcomed, however: The head-brain does not like being told, in effect, that it has been sharing space all these years not with a primitive, nocturnal, mental ball of rags à la Freud but with a full-fledged "second brain"-a bigger brain that never sleeps, whereas the head-brain must suffer the indignity of its nightly mortality. If the alarm clock scenario could be articulated as a communique from body-brain to head-brain, I believe it would go something like this:

"I'm not just a fantasy realm that churns out dream-stuff. You should realize that I also register sensory input, i.e., that I have perceptions. In fact, between the two of us, I'm the only one with perception. Your so-called perceptions are just an echo in your cranium of my genuine perceptions. True, when communicating with you I may seem slow, but my perceptions of the outside world operate close to real time, a feat that is physically impossible for you! Which is worse: to be a slow speaker with both feet on the ground or to be a mute off-kilter time-lagged observer?"
Thus far, for the "alarm clock dream", the primary point of reference has been Libet et al. (1979), which deals only with the mental timing puzzle; we return now to Libetology in the larger sense, where the focus is on (our notion of) volition. Suppose I lie in bed for a few seconds or minutes after hearing the alarm. Eventually, there must come that magic time, say 7:01:35 a.m. or 7:08:21 a.m. for argument's sake, when I actually start to get up, e.g., by throwing the covers off. Which of my two brains do you suppose chooses that particular moment for my hands to "impulsively" throw the covers off? Per Figure 1, it must be the body-brain. A related vignette: When I look in the mirror, someone (a personage) looks back. Who is it? I believe it is my body-brain looking back at my head-brain, mano a mano-hence the eeriness sometimes associated with this experience, if it is late at night and the defenses are down from lack of sleep.

\section{Hinduism}

Their spiritual insights aside, the Hindus happen also to be the most ancient and accomplished of introspection specialists. So their viewpoint must be incorporated - or at the very least acknowledged - in any such discussion. Happily, one finds that there is no particular problem accommodating most of the ideas discussed so far in this paper with the Vedānta model. I've based Figure 2 below on passages similar to the following:

Waking, dreaming, and dreamless sleep, the three states of consciousness, are dissolved in the turiya, the transcendental. Once more the bell rings. The sound Om is heard and as it were a heavy weight falls on the bosom of the calm, infinite ocean; immediately the ocean becomes agitated. From the bosom of the absolute rises the relative... from the transcendental come the three states of consciousness... Again the waves dissolve in the ocean, and there is the great calm...innumerable worlds issue from the ocean and go back into it... Just as, through intense cold, some portions of the ocean freeze into ice and the formless water appears to have form, so, through the intense love of the devotee, Brahman appears to take on form....from Śrī Śr̄ Rāmakrsna Kathāmrta as translated by Prabhavananda (1963), pp. 346 and 289

Related images occur in Prabh. (1963) pp. 349 and 357.

In the Legend for Figure 2, we say Ātman is the true Self. But that simplistic definition needs to be supplemented by the following:

In one passage [of the Katha Upanisad] the Ātman is described as enclosed in a series of sheaths:

One must pass through annamaya, the food-body; prānamaya, the vital principle; manomaya, the mind; vijñānamaya, the intellect; ānandamaya, bliss/ego; and the unmanifested seed, only then arriving at the Self [Ātman], the unconditioned, knowing whom one attains to freedom and achieves immortality (after Prabh, 1963: pp. 52-53, by merging his two lists).

In the context of Hinduism, one is struck by the following passage in Penrose: "Perhaps consciousness is, after all, merely a spectator who experiences nothing but an 'action replay' of the whole drama" (Penrose, 1989: p. 443). At first one thinks, "Ah, another convergence of east and west!" But look again. Penrose's rumination is actually the inverse of the model where Ātman, the true Self, is a silent and constant witness to ego. Thus we are reminded that metaphors are alluring but treacherous. Not to say the one metaphor is "correct" and the other "incorrect". I would rather just mark all verbiage with a "DANGER" sign and leave it at that. 


\section{Triptych and Concluding Remarks}

Sources for the triptych in Figure 3 below: The first panel is distilled from Figure 1 but with the lingering Freudian terms $\mathrm{X}$ 'd out (also, sans "programming line", to be revisited in due course). The second panel contains my attempt to summarize Rossi \& Cheek (1994) in a mini-mandala. The third panel repeats key terms from Figure 2.

The content of the first two panels may be characterized as binary: The first shows an event's Inception (I) versus its illusory moment of being Willed (W) only later. The next one depicts another binary paradigm: the body-brain and head-brain working not so much in parallel as with the former encompassing the latter, and/or "standing behind it".
By contrast, the paradigm of the Upanișads is a trinity, comprised of Brahman-Ātman-māyā. From this trinity, the temporary dichotomy Brahman/māyā or the temporary dichotomy Brahman/Ātman may be extracted to facilitate discussion. (Also, a fourth piece, ego, may be temporarily appended, as in Figure 3). Focusing then on the Indic scheme's binary aspects for a moment, we may draw a parallel between it and the simpler paradigms to the left, to arrive at a distillation of all three panels:

*** from a solid foundation, something ephemeral arises and is (mis)perceived by the ego as the sole reality ***

This is the shared motif that runs through all three. But what has become of the "programming line" in Figure 1 that I said was so important? For brevity's sake, let's allow the middle

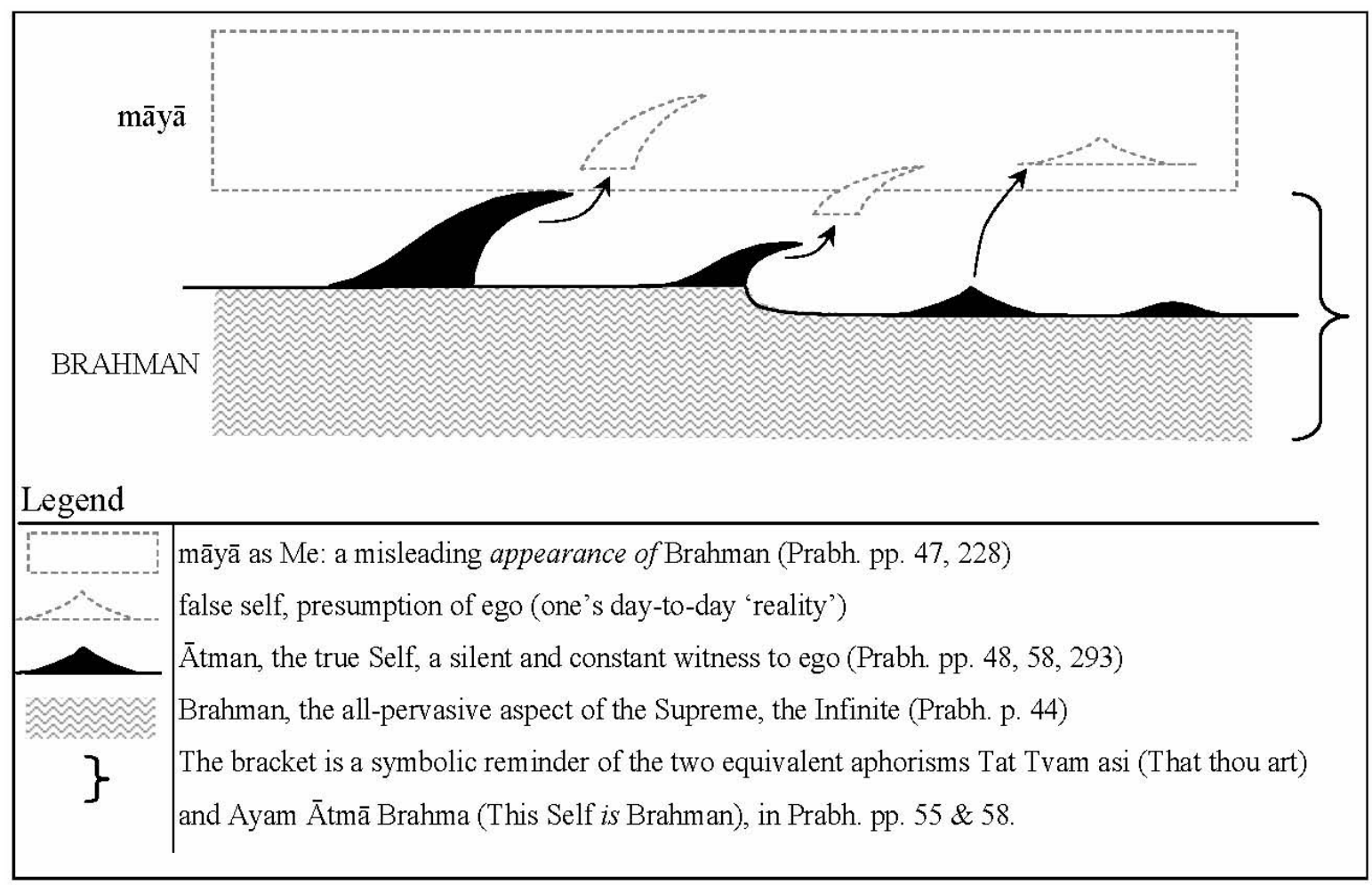

Figure 2.

An ocean metaphor, from hinduism.

\begin{tabular}{|c|c|c|c|}
\hline 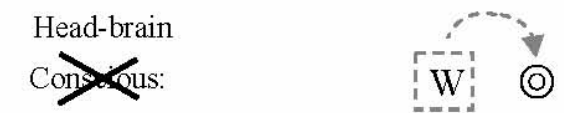 & Head-brain & māyā & ego (false self) \\
\hline $\begin{array}{l}\text { Body-brain } \\
\text { Uncosious: I }\end{array}$ & Body-brain & Brahman & Ātman (true Self) \\
\hline Libetology & $\begin{array}{l}\text { Hypnotherapy } \\
\text { à la Rossi \& Cheek }\end{array}$ & \multicolumn{2}{|c|}{ The Hindu trinity (plus ego) } \\
\hline
\end{tabular}

Figure 3.

Triptych. 
panel to serve double duty as a picture of the head-brain "programming" the body-brain.

Here is another aspect of the three-way relationship between Libetology, Rossi \& Cheek, and Hinduism:

1) Given the relative newness and mystery of Libetology, it could benefit from being "legitimized" or "authenticated" by Hinduism - the most ancient and detailed introspection system. If one believed absolutely in the connections I'm proposing, then one might want to construct a mandala that followed a "nested" scheme as follows:

\section{$\{[($ Libetology $)$ hypnotherapy $]$ Hinduism $\}$}

I've deliberately avoided that approach since it would tend to inhibit rather than invite more discussion. I prefer the deliberately rough analogies suggested by Figure 3.

2) Conversely, one could say that Hinduism "needs" Libetology to help explain why it is so difficult to modify or even observe one's own actions/thoughts. Libetology shows how the driving force for thoughts and actions is always a half-second ahead of the would-be observer of "now". Small wonder that learning how to meditate (or to truly take Responsibility) is very difficult.

3) Rossi \& Cheek provide hope for a mechanism capable of breaking into the cycle alluded to in 2) above. The key is the realization that the body-brain is real, sharp and "approachable", not the dull, amorphous, recalcitrant, blob evoked by Freud's “id" (previously Freud's "unconscious").

What finally shall we make of this life on a half-second delay? Outside the technical details and outside the possible resonance with eastern thought, what might be the implications of Libetology for "the rest of us" in developing a day-to-day philosophy of life? One possible reaction is to simply laugh Libetology off as an oddity: "We all live together on the same delay, so no harm done." Wrong. So long as one continues to denigrate the body-brain by calling it the "subconscious" or worse yet the "unconscious" he/she can slip easily into a situation of mortal danger, seemingly beyond one's control. The first step toward breaking out of this difficulty is to acknowledge and to "talk" seriously to one's real brain (i.e., to the body-brain, the one that never sleeps and has the better grasp of "real time" and basically runs the show). The story "Split/Brain" by Joyce Carol Oates is dedicated to this very problem, where she shows persuasively that sometimes the dialogue between the two brains is indeed a matter of life and death.

\section{REFERENCES}

Baumeister, R. F., Mele, A. R., \& Vohs, K. D. (Eds.) (2010). Free will and consciousness: How might they work? Cambridge, MA: Oxford University Press. 225.

Buonomano, D. (2011). Brain bugs: How the brain's flaws shape our lives. New York: W.W. Norton.

Dorje, G. Jr. (2006). The Tibetan book of the dead. Viking. 535.

Eccles, J. C. (1994). How the self controls its brain. Berlin: SpringerVerlag. 197.

Hallett, M. (2007) Volitional control of movement: The physiology of free will. Clinical Neurophysiology, 118, 1179-1192. doi:10.1016/j.clinph.2007.03.019

Hughes, G., Velmans, M., \& De Fockert, J. (2009). Unconscious priming of a no-go response. Psychophysiology, 46, 1258-1269. doi:10.1111/j.1469-8986.2009.00873.x

Klein, S. (2002a). Libet's research on the timing of conscious intention to act: A commentary. Consciousness and Cognition, 11, 273-279. doi:10.1006/ccog.2002.0557

Klein, S. (2002b). Libet's timing of mental events: Commentary on the commentaries. Consciousness and Cognition, 11, 326-333. doi:10.1006/ccog.2002.0569

Kornhuber, H. H., \& Deecke, L. (1965). Hirnpotentialänderungen bei willkürbewegungen und passiven bewegungen des menschen: Bereitschaftspotential und reafferente potentiale. Pflügers Archiv für $\mathrm{Ge}$ samte Physiologie, 284, 1-17.

Kühn, S., \& Brass, M. (2009). Retrospective construction of the judgment of free choice. Consciousness and Cognition, 18, 12-21. doi:10.1016/j.concog.2008.09.007

Lederman, L. M., \& Hill, C. T. (2008). Symmetry and the beautiful universe. New york: Prometheus Books. 363.

Lee, T. D. (1988). Symmetries, asymmetries, and the world of particles. Washington, DC: University of Washington Press. 66.

Libet, B., Wright, E. W. Jr., Feinstein, B., \& Pearl, D. K. (1979). Subjective referral of the timing for a conscious sensory experience. Brain, 102, 193-224. doi:10.1093/brain/102.1.193

Libet, B., Gleason, C. A., Wright, E. W., \& Pearl, D. K. (1983). Time of conscious intention to act in relation to onset of cerebral activity (readiness-potential). The unconscious initiation of a freely voluntary act. Brain, 106, 623-642. doi:10.1093/brain/106.3.623

Libet, B. (1985). Unconscious cerebral initiative and the role of conscious will in voluntary action. Behavioral and Brain Sciences, 8 , 529-539. doi:10.1017/S0140525X00044903

Libet, B. (1999). Do we have free will? Journal of Consciousness Studies, 6, 47-57.

Libet, B. (2006). Reflections on the interaction of the mind and brain. Progress in Neurobiology, 78, 322-326. doi:10.1016/j.pneurobio.2006.02.003

Matsuhashi, M., \& Hallett, M. (2008). The timing of the conscious intention to move. European Journal of Neuroscience, 28, 23442351. doi:10.1111/j.1460-9568.2008.06525.x

Murphy, N., Ellis, G. F. R., \& O'Connor, T. (Eds.) (2009). Downward causation and the neurobiology of free will. Berlin: Springer. 292.

Oates, J. C. (2010). Split/brain. Give me your heart. Boston: Houghton Mifflin Harcourt. 15-21.

Obhi, S. S., \& Haggard, P. (2004). Free will and free won't. American Scientist, 358-365. doi:10.1511/2004.4.358

Penrose, R. (1989). The emperor's new mind. Cambridge: Oxford University Press.

Pockett, S. (2004). Hypnosis and the death of "subjective backward referral". Consciousness and Cognition, 11, 621-625. doi:10.1016/j.concog.2004.06.005

Popper, K. R., \& Eccles, J. C. (1977). The self and its brain. Berlin: Springer-Verlag. 597.

Prabhavananda (1963). The spiritual heritage of India. Hollywood: Vedanta Press.

Rossi, E. L., \& Cheek, D. B. (1994). Mind-body therapy: Methods of ideodynamic healing in hypnosis. New York: W.W. Norton. 519.

Schooler, J. W. (2010). What science tells us about free will. Baumeister. 191-218.

Searle, J. R. (2010). Consciousness and the problem of free will. Baumeister. 121-134.

Velmans, M. (1991). Is human information processing conscious? Behav Brain Sci, 14, 651-726. doi:10.1017/S0140525X00071776

Velmans, M. (2003) Preconscious free will. Journal of Consciousness Studies, 10, 42-61.

Vohs, K. D. (2010). Free will is costly: Action control, making choices, mental time travel, and impression management use precious volitional resources. Baumeister. 66-81.

Wegner, D.M. (2002). The illusion of conscious will. Cambridge: MIT Press. 


\section{Appendix A: Sources for Figure 1}

My Figure 1 is a distant relative of Figure 2, "Timing of subjective events and the Bereitschaftspotential (readiness potential, RP) with data from Libet et al. (1983)", and Figure 6, 'Possible timing of subjective events in comparison to measurable events in the course of making voluntary movements', in Hallett (2007), pp. 20 and 24. I've reworked Hallett's graphs as follows: 1) For clarity, I've relabeled his minus $1000 \mathrm{~ms}$ as my time zero; 2) To properly dramatize the key findings, I've combined his "Real World Time" scale with his "Actual Time of Perception" scale, to form a single time line (In his Figure 6, Hallett includes a third scale called "Ascribed Time of Perception". This, too, I acknowledge in Figure 1, by way of the dashed lines at 750 and $900 \mathrm{~ms}$ ); 3) I've "boldly" broken tradition by relabeling "RPI" (=Readiness Potential One) as "I" = Inception (Unless one is proposing that each adult thought has asymptotic roots dangling all the way back to the subject's infancy, one should make way for the commonsense proposition that a thought has its moment of inception "today". And while we wait another decade or two to confirm the precise time/space parameters for inception, why not admit that we believe already with great confidence that the RPI is it?); 4) Commonsense dictates that we round out the picture with something akin to my "programming" arrow. Without some such provision for closing the loop, it would seem that one believes his only audience is the myopic specialist in a sub- basement lab. With loop closure, we have a model that acknowledges the elephant in the room, namely: "How the heck does all this work in general, in real people, in full cycles?"

Further details about time lines, labeling and rounding: A time line labeled "Real World Time" in Hallett's Figure 6 shows RPI somewhere to the left of $-1000 \mathrm{~ms}$. More specifically, he says: "With thoughtful, preplanned movements, the BP began about $1050 \mathrm{~ms}$ prior to EMG onset" (Hallett, p. 3), where "BP" = Bereitschaftspotential = "RPI" = Readiness Potential One = my "I" for Inception, and "EMG" = Electromyography $=$ the physical event in question $=$ my "solid center" icon. I round his $1050 \mathrm{~ms}$ to 1000 then flip the scale eastto-west so that his " 0 " becomes my (positive) " $1000 \mathrm{~ms}$ " mark. Next, I merge Hallett's time line labeled "Actual Time of Perception" into my combined time line. Implicitly, the "W" on his middle time line would fall at $+108 \mathrm{~ms}$ on his top time line. Let's call this $+100 \mathrm{~ms}$ in round figures. Accordingly, I place "W" at $(1000+100=) 1100 \mathrm{~ms}$ on my combined time line. In Hallett, "M" is separated from "W" by $([-90]-[-250]=)+160$ $\mathrm{ms}$ (in both his Figures 2 and 6). In my graphic, the corresponding interval is the $(1250-1100=150 \mathrm{~ms})$ separation of my "hollow center" icon from "W". In other words, I have rounded his implicit $160 \mathrm{~ms}$ to an arbitrary but explicit $150 \mathrm{~ms}$. The impetus for introducing the changes described in this appendix was to demystify the presentation.

i.e., as difficult as my way may seem at first, the traditional way in the literature is far more difficult to follow. 